\title{
Grupo de Convivência em Saúde Mental: perspectivas de usuários e a experiência do curso de Terapia Ocupacional da Universidade Federal do Paraná*
}

\section{Convivial Group and Mental Health: user's perspective and the experience of Occupational Therapy Course of Federal University of Paraná}

\author{
Luís Felipe Ferro ${ }^{1}$, Mônica de Macedo Cardoso ${ }^{2}$, Giovana Fedato ${ }^{3}$, \\ Caroline Cristina Fracaro ${ }^{4}$
}

\begin{abstract}
FERRO, L. F.; CARDOSO, M. M.; FEDATO, G.; FRACARO, C. C. Grupo de Convivência em Saúde Mental: perspectivas de usuários e a experiência do curso de Terapia Ocupacional da Universidade Federal do Paraná. Rev. Ter. Ocup. Univ. São Paulo, v. 23, n. 2, p.146-152, maio/ ago. 2012.

RESUMO: A atual Política Pública de Saúde Mental direciona suas ações para construir a inclusão social de sua população alvo. Neste contexto um dos recursos utilizados são os Grupos de Convivência. Com a intenção de investir na inclusão social dos usuários atendidos, foi estruturado um grupo de convivência a partir da parceria do curso de Terapia Ocupacional da Universidade Federal do Paraná com a Associação Arnaldo Gilberti, localizada na cidade de Curitiba. Com vistas a proporcionar subsídios para a apresentação do relato da experiência de 3 anos junto ao grupo, propôs-se a realização, em 2011, de uma pesquisa de campo exploratória e de caráter qualitativo a partir de entrevistas não-estruturadas com 11 sujeitos participantes do grupo. Observou-se a importância do grupo para proporcionar encontros, ampliando a rede social de apoio dos usuários e sua relação com seu território. Enquanto problemáticas para a participação no grupo constatou-se a falta de apoio familiar e a fragilidade ainda presente na conquista da autonomia do grupo. Destaca-se a necessidade de acompanhamento do grupo por profissionais e da continuidade das ações enquanto estratégia para proporcionar de maneira efetiva a inclusão social de usuários.
\end{abstract}

DESCRITORES: Saúde mental; Terapia ocupacional; Grupos de treinamento de sensibilização; Assistência à saúde; Serviços de saúde; Saúde pública.

\footnotetext{
* Trabalho vinculado ao projeto de pesquisa: "Grupo de Convivência em Saúde Mental: potencialidades e limitações sob a ótica de usuários" do departamento de Terapia Ocupacional da Universidade Federal do Paraná (UFPR).

1. Docente da Universidade Federal do Paraná (UFPR).

2. Docente da Universidade Federal do Paraná (UFPR)

3. Discente do curso de Terapia Ocupacional da Universidade Federal do Paraná (UFPR).

4. Discente do curso de Terapia Ocupacional da Universidade Federal do Paraná (UFPR).

Endereço para correspondência: Av. Prefeito Lothário Meissner, 632 - Jardim Botânico - Curitiba - CEP: 80210-170 - Campus Botânico (UFPR). Departamento de Terapia Ocupacional.
} 


\section{INTRODUÇÃO}

$1 \begin{aligned} & \text { assunção do modelo de reabilitação } \\ & \text { psicossocial para o embasamento da atual } \\ & \text { política pública no campo da saúde mental }\end{aligned}$ direciona o foco de atenção da saúde para o indivíduo em seu território e para a construção da cidadania e protagonismo social (BRASIL, 2004a,b). A partir desta premissa um novo cenário é apresentado para a composição de ações estratégicas em saúde mental.

A exclusão, débito histórico adquirido pela sociedade em relação à população com transtornos mentais submetida ao modelo manicomial, passa a ser enfrentada por meio da estruturação de serviços territoriais, que atualmente adotam a meta da inclusão social (NICÁCIO; CAMPOS, 2005).

Orientadas pela política pública de saúde mental, ações e serviços realizam seus esforços no sentido de potencializar as possibilidades de trocas sociais de sua população alvo.

Diversas intervenções em saúde passam a ser organizadas em conjunto com a comunidade e suas potencialidades. Grupos de geração de trabalho e renda, projetos da saúde em parceria com escolas, espaços de cultura, lazer e esporte, intervenções diversas e criativas passam a compor a rede social de apoio ao indivíduo com transtorno mental, possibilitando a meta da inclusão social (LOPES, 1999; FONSECA, 2008).

As redes sociais de apoio proporcionam suporte e proteção às questões de saúde do indivíduo, sendo constituídas por vínculos de parentesco, amizade, vizinhança, assim como por relações com equipamentos sociais diversos, mercado, terceiro setor e trocas de serviços (SOUZA et al., 2009).

É a partir deste panorama que o curso de Terapia Ocupacional da Universidade Federal do Paraná (UFPR), em parceria com a Associação Arnaldo Gilberti, na cidade de Curitiba, compõe propostas de intervenção, por meio de estágios curriculares, com foco na inclusão social da pessoa com transtorno mental, tendo como um de seus recursos um Grupo de Convivência.

A intenção deste trabalho é apresentar o relato da experiência de 3 anos na condução do grupo pelos docentes responsáveis pelos estágios, tendo como ponto de apoio os relatos dos usuários do grupo.

\section{Métodos}

O presente artigo é vinculado ao projeto "Grupo de Convivência em Saúde Mental: potencialidades e limitações sob a ótica de usuários", aprovado pelo Comitê de Ética em Pesquisa (CEP/UFPR) sob o número 1074.199.10.12.
A partir de uma pesquisa de campo de caráter qualitativo e exploratório (MARCONI; LAKATOS, 2007), conduzida em 2011, foram realizadas entrevistas não-estruturadas com 11 sujeitos participantes do Grupo de Convivência. Todas as entrevistas foram gravadas e transcritas. Os sujeitos foram convidados a participar da pesquisa, que ocorreu com o consentimento expresso dos usuários, obtido a partir da assinatura do Termo de Consentimento Livre e Esclarecido.

Para a análise do material, realizaram-se os seguintes procedimentos, conforme proposto por Yin (2010): exame; categorização; tabulação; e recombinação das evidências.

Relatórios, reuniões de supervisão e grupos de estudo, próprios à estrutura organizativa dos estágios curriculares em saúde mental do curso de Terapia Ocupacional da UFPR, proporcionaram momentos de reflexão crítica e impulsionaram a elaboração de diferentes práticas e ações junto ao grupo.

Desta forma, intenciona-se associar a perspectiva dos usuários e o relato da experiência de coordenação do grupo de maneira a proporcionar encontro profícuo para fortalecer reflexões sobre o grupo e a atuação dos terapeutas ocupacionais.

\section{Grupo de convivência em saúde mental: limitações e potencialidades}

\section{Curso de Terapia Ocupacional da UFPR e o Grupo de convivência: breve histórico}

Segundo Borges et al. (2008), a emergência dos grupos de convivência remonta a década de 1970, na qual o Serviço Social do Comércio (SESC) de São Paulo através de um programa para a terceira idade, passou a proporcionar este serviço a idosos.

Desde então, os grupos de convivência de idosos vêm proliferando em clubes, paróquias, associações comunitárias, centros de saúde e instituições de ensino superior. Esses grupos realizam atividades variadas, de cunho recreativo, cultural, social, educativo e de promoção da saúde (BORGES et al., 2008, p. 2799).

Os grupos de convivência intencionam enfrentar o isolamento social de determinados indivíduos e/ou grupos sociais de maneira a criar "...espaço que favoreça o encontro e o desenvolvimento global dos participantes" (OLIVEIRA et al., 2004, p. 277).

Procurando ampliar a rede social de apoio dos usuários dos serviços de saúde mental, o curso de Terapia Ocupacional vem trabalhando, desde 2008, na organização e proposição de um grupo de convivência vinculado ao estágio curricular em saúde mental. Subsidiados pelo modelo da Reabilitação 
Psicossocial, o grupo vêm se estruturando na direção de promover a inclusão social de pessoas com transtorno mental.

$\mathrm{O}$ grupo é vinculado à Associação Arnaldo Gilberti (AAG), voltada ao atendimento e defesa dos direitos da pessoa com transtorno mental. A AAG apresenta relação com a Prefeitura de Curitiba, que auxilia a instituição no pagamento de aluguel, telefone, água e luz. A instituição conta, para proporcionar atividades à população alvo, com diversos voluntários e com a parceria com o curso de Terapia ocupacional da UFPR, além de gerenciar dois Serviços Residenciais Terapêuticos do município.

Os participantes do grupo de convivência utilizam-se de serviços de saúde mental e foram encaminhados à AAG por indicações de outros usuários e/ou por profissionais de saúde da região.

O grupo de convivência, coordenado por um terapeuta ocupacional, conta com a participação de 4 a 6 estagiários e se reúne semanalmente na AAG por um período de 4 horas para a realização de visitas a espaços sociais (parques públicos e temáticos, museus, etc). Tem como principais objetivos promover a ampliação da rede social de apoio do usuário, favorecendo os vínculos entre os usuários e destes com os diversos pontos/equipamentos/instituições da cidade. A programação do grupo é realizada a partir do levantamento inicial das demandas dos usuários.

O grupo possui a característica de ser pouco aberto (BALLARIN, 2003), contando com o máximo de 20 vagas. Em 3 anos de trabalho, o grupo acolheu cerca de 40 pessoas, contando com participação mais frequente de 12 pessoas.

A partir desta experiência, foi estruturada uma pesquisa para analisar a vivência dos usuários, destacando as dificuldades e potencialidades do grupo para contemplar os objetivos aos quais se propõe.

A análise dos dados nos conduziu à elaboração de 4 categorias, apresentadas a seguir, que proporcionaram base para a apresentação crítica do relato da experiência. Os sujeitos serão identificados pela letra ' $\mathrm{S}$ ', seguidos de um número.

\section{Relacionamentos e o Grupo de Convivência: abertura ao encontro}

...relacionamento é tudo na vida da gente... em todos os aspectos, em todas as situações da vida da gente (S3).

Os relatos obtidos ofereceram subsídios para explorar um dos objetivos principais do grupo de convivência: proporcionar ampliação da rede social de apoio por meio do fortalecimento de vínculos entre os componentes do grupo.

Para um participante o grupo:
Melhorou minha vida social. Depois que comecei a freqüentar aqui... Essa integração com as pessoas né, com estas pessoas que freqüentam aqui... melhorou. Foi bom pra mim. $O$ aspecto social...(S5)

Outros sujeitos relatam a potencialidade do grupo para promover trocas sociais:

Porque a gente fica em contato com a natureza,.. a gente pode fazer amizades, a gente pode aprender com os filmes, com as atividades.(S2)

Os relatos evidenciaram a potencialidade do grupo para promover a ampliação da rede social de apoio. Contudo, os relatos a seguir apontam que o grupo possibilita, acima de tudo, encontros, que possuem belezas diversas e dificuldades relacionais a serem superadas. Ao terapeuta cabe a elucidação sobre os enfrentamentos a serem manejados.

O intuito desse programa, desse passeio, dessa atividade será, deixar bem claro pra quem quiser ir, que não vou lá pra, encher a barriga, né? Falando num modo chulo, mas pra aprender, pra conviver, pra......saborear a atividade de uma outra forma, não só comendo... (S2)

Os passeios são acompanhados de lanches comunitários, trazidos e compartilhados pelos usuários. As relações humanas são permeadas de conflitos e interessa explicitar algumas dificuldades presentes no desenvolvimento dos grupos, afirmando a necessidade de mediação de diferentes situações para estimular o grupo na construção de um processo criativo e saudável - papel desempenhado pelo terapeuta vinculado ao grupo.

Benefícios diversos puderam ser evidenciados, contudo é necessário não atribuir as melhoras identificadas nos componentes do grupo apenas a sua relação exclusiva com o grupo. O relato a seguir afirma a importância do grupo, contudo se enfatiza a necessidade de vislumbrar, o panorama diverso de ações e vivências experienciados pelos usuários, que extrapolam ao grupo, em conjugação com sua rede social de apoio e com seu processo terapêutico.

Eu era muito fechada nem sabia que existia tanta coisa legal e com o Grupo de Convivência vi que você tem saídas pra quando você tiver com uma depressão (...) Uma coisa muito importante que aconteceu, (...), eu não me alimentava com meu marido e com meu filho. Eu ia num cantinho comer um prato de comida, eu não conseguia me alimentar do lado (...) Eu era um bichinho. e eu to conseguindo levantar a cabeça e me sentir como um ser humano normal... porque a 
doença foi me recalcando tanto....(S8)

A inclusão social, proporcionada pelo grupo, insere pessoas em contextos sociais, abrindo margem para o encontro humano que, embora cheio de asperezas, coloca em andamento, sim, o jogo imperfeito e sedutor da vida.

\section{demandas}

\section{Grupo de convivência, programação, território e}

O desenvolvimento de qualquer intervenção requer algo que diversos profissionais da saúde esquecem-se no processo de composição de suas ações: usuários e suas demandas.

Sabe aquelas pinturas? Que vem com contorno, ai você vai pintando, igual coisa de primário (...) aquilo assim eu acredito de alguma forma organizava... a pessoa se preocupa com a cor, com a forma, com a estética, tem o seu proveito, tem o seu valor mas eu não sou muito hábil nisso, com os passeios eu sou sincero que eu me sinto muito bem, agora com cortes de...de jornais (...) Olha, sinceramente o passeio eu acho uma coisa maravilhosa, é uma coisa que me agradou muito. (S6)

Este relato expõe uma situação comum aos serviços de saúde mental. Diversas propostas terapêuticas são elaboradas por profissionais e oferecidas ao usuário de maneira vertical e sem relação de composição com seu público alvo. Autores diversos (MANGIA et al., 2002; SARACENO, 1998), assim como documentos oficiais (BRASIL, 2004, 2011), criticam a imposição unilateral de determinada atividade/intervenção, reposicionando a ação em saúde na diretriz do acolhimento (SÃO PAULO, 2002).

$\mathrm{O}$ acolhimento inverte a lógica positivista da intervenção terapêutica. Ao invés de procurar intervenções padronizadas para cada patologia, propõe que a composição da intervenção deva acontecer a partir do encontro singular com cada usuário. A partir das demandas da população, as práticas seriam pensadas e estruturadas, contando com uma rede social de apoio territorial, para responder às necessidades individuais e coletivas da população (OLIVEIRA, 2007; BOCCARDO et al., 2011).

O relato apresentado inicialmente aponta para a pergunta: Por que muitos terapeutas ainda compõem projetos terapêuticos singulares a partir de atividades que não ressoam no cotidiano do usuário?

O projeto terapêutico deve espelhar o que usuário, família, comunidade demandam construir enquanto projeto de vida, em seu processo de inclusão social (OLIVEIRA, 2007).

O grupo de convivência foi proposto para enfrentar uma demanda clara dos usuários: o isolamento.

Na verdade fiquei preso tanto tempo lá em São Paulo, dentro do apartamento e em casa assim eu, fico preso dentro de casa (...) me sinto isolado, muitas vezes não faço nada pra mudar isso e muitas vezes a situação não se mostra propicia (...) as pessoas que tem esse tipo de conduta encontram aqui um bom motivo pra sair do isolamento né?! (S6)

A programação do grupo é composta em conjunto com os usuários. No início de cada semestre, ocorrem encontros entre terapeutas, estagiários e usuários e se organiza a programação dos encontros, a partir de levantamento prévio, realizado pelos terapeutas e estagiários, da programação de espaços diversos (culturais, da educação, saúde...).

O grupo proporciona abertura para experiências e, muitas vezes, envereda-se por atividades que não agradam, mas que, contudo, compõem em concomitância com outras atividades, uma história própria ao grupo, que passa paulatinamente a carregar consigo intimidades de um grupo singular.

Pergunto pra todo mundo "conhece Recanto Saltinho? Não! Aonde? Nossa, você tem que ir lá, tem que ir lá pra aproveitar a natureza, ir lá com a tua família, (...) Desde o nosso passeio eu vi o passeio de uma outra forma (...) estar em contato com a areia, com o mar, a caminhada, estar junto com o outro (...) aproveitar cada momento (...). E... outros também, cinema, da gente poder compartilhar um saquinho de pipoca, um refrigerante com o teu amigo. (S2)

As visitas ao território ampliam o circuito dos usuários e o conhecimento sobre a cidade. A ampliação de laços afetivos com a comunidade e território, proporcionam intimidade, particularidade e alegrias singulares ao indivíduo em sua relação com o mundo e consequentemente seu enraizamento (WEIL, 2001).

\section{Rede social de apoio: ampliação e suporte}

A rede social de apoio, constituída por relacionamentos entre amigos, vizinhos, parente, colegas, apresentou em diferentes relatos restrição substancial às relações familiares nucleares.

Meu ciclo de amizades é bem, curto (...) Dificilmente, eu tenho amizade... (S1)

Porque o psiquiatra, ele te dá o remédio e você fica 
entre 4 paredes ali e a familia toda que é normal ela tá vivendo a sua vida: vai trabalhar, faz alguma coisa, e você fica entre 4 paredes.(S8)

Tais situações são conhecidas pelos profissionais de saúde mental e alguns autores mostram a restrição da rede vivenciada pelos usuários (MÂNGIA; MURAMOTO, 2007; BAZHUNI, 2011). A saúde mental deve investir, por meio de diferentes intervenções, na inclusão social de sua população alvo (BRASIL, 2004).

O grupo de convivência adota esta diretriz e se apresenta como um recurso para a qualificação da rede social, a qual oferece " apoio instrumental e emocional à pessoa, em suas diferentes necessidades (...) [pois] os suportes sociais recebidos e percebidos pelas pessoas são fundamentais para a manutenção da saúde mental (DESSEN; BRAZ, 2000, p.221-2).

Contudo, identifica-se a falta de compreensão do objetivo do grupo por familiares.

O maior beneficio (...) aprender a conviver em grupo, só que nem sempre o que a gente aprende aqui, às vezes os familiares não entendem e a gente não pode compartilhar em casa. Acham, vêem as coisas de uma outra forma, criticam, acho que a gente vem pra zuar, pra passar o tempo, pra ficar não fazendo nada...(S2)

Nas práticas em saúde mental há necessidade de envolver a família, contudo autores destacam a baixa adesão dos familiares nos tratamentos (CARNEIRO; ROCHA, 2004; SILVA; SANTOS, 2009).

Os serviços de saúde precisam criar estratégias para envolver a família no tratamento. $\mathrm{O}$ grupo de convivência desenvolveu algumas estratégias, como: passeios envolvendo familiares e usuários; aproximação e contato sistemático com a família.

Autonomia e a prática do grupo de convivência: desafios e potencialidades

Este tópico visa concluir a apresentação dos dados que, da mesma maneira que a prática junto ao grupo, incita diferentes reflexões.

Oliver et al. (2004), em estudo sobre um grupo de convivência realizado no bairro Jardim D'Abril (SP), apontam a dificuldade para a auto-organização pelos usuários e familiares vinculados ao grupo, assim como certa dependência dos profissionais, como uma das causas de seu término. De acordo com esses achados, algumas observações advindas da prática da coordenação do grupo, sustentadas por relatos dos sujeitos, demonstraram a baixa autonomia de participantes para auto-organização. Ao serem perguntados sobre suas férias e possíveis encontros com participantes do grupo, os entrevistados mostram que se mantiveram isolados e sem contato com outros participantes:

Ah, dormi bastante, assisti bastante televisão. (S4)

Não falei com ninguém e também não sai pra nenhum lugar não. (...) Fiquei aqui na cidade. (S5)

Evidencia-se a postura passiva dos usuários e ausência de movimento de auto-organização por parte do grupo. Foram formuladas estratégias para enfrentar esta problemática e uma das ações consistiu em incentivar a organização de passeios pelo próprio grupo.

Os relatos apontaram também para fragilidades nas repercussões dessa estratégia:

Duas vezes que eu vim no grupo de convivência que o grupo organizava, ficou assim uma má vontade de organizar. Não sei, mas é válido, porque a gente pode tentar pelo menos, vocês podem deixar pra gente: até tal prazo vocês podem organizar, mas se vocês não organizarem a gente... ai vocês fazem uma outra coisa dai. (S1)

Alguns relatos dos participantes procuraram atribuir sentido para a falta de iniciativa do grupo para a autoorganização. Quando inquiridos sobre os motivos que julgam dificultar este movimento relatam:

Ah! O pessoal precisa se entrosar mais, não só esperando os estagiários (...) Ah, falta autonomia do povo, né. Por que não tem. (S4)

Eu não consigo tomar atitude,? Eu tenho mil ideias mas não consigo sair e ir lá sozinha no parque. Esses dias a gente ficou programando um monte de atividades, de cursos, eu a N.H. e a S.T. (...), parece que tem uma força maior que a gente não consegue tomar atitude de ir lá, fazer uma carteira de trabalho, ir lá fazer um curso, participar de uma atividade de lazer sozinhos final de semana, não sei o que é isso, uma insegurança. (S2)

As ações vêm acontecendo e algumas iniciativas são observadas. Perguntas foram direcionadas aos sujeitos no sentido de obter informações sobre a frequência de passeios dos usuários no período de férias do grupo de convivência:

Tá muito baixa. A única coisa que eu to fazendo de bom é que eu to indo com a $N$. [participante do grupo] na Federação Espirita. (S8) 
Vejo a S. Ah! Com a S. eu saio bastante, sabe a S. né? Toda sexta-feira eu vou à tarde na federação espirita com ela. (S3)

E eu até tenho umas fotos que eu tirei no meu celular... fizemos um churrasquinho lá. Eu, o $H$., a K., a Y., a dona $W .$, o Q.,o P... (S9)

A autonomia para a realização auto-organizada do grupo é uma construção cotidiana, que enfrenta diferentes desafios, desde possíveis flutuações, próprias ao transtorno mental, a investimentos e estratégias para processualmente construí-la em seu cotidiano.

Contudo, apresenta-se de maneira substancial a importância da continuidade das ações e acompanhamento estreito do grupo no processo de auto-organização e, talvez, a construção prática do processo de desligamento. Este desligamento não se refere ao abandono do grupo e seus usuários à própria sorte, mas ao distanciamento gradual de profissionais a ele vinculado garantindo, no entanto, acompanhamento cuidadoso, mesmo que mais espaçado temporalmente, de maneira a responsabilizar-se pela sua continuidade.

\section{Conclusão}

Entrevistadora: Vocêpretende continuar freqüentando o grupo de convivência nos próximos meses? Por quê?

S4: Sim! Vou! Faz parte um pouco da minha vida também.
Entrevistadora: Você se sente parte do grupo, então? S4: Faço parte do grupo, sempre...

Entrevistadora: E se o grupo de convivência parasse hoje, como seria?

S4: Dai pararia tudo, né...

A discussão sobre o Grupo de Convivência centrada apenas em seu papel e benefícios na ampliação das redes sociais de apoio não é suficiente, pois os processos de inclusão social necessitam de práticas e reflexões que mostrem concretamente as dificuldades e potencialidades vivenciadas em seu percurso de construção.

Para finalizar, além de mostrar a importância do grupo de convivência, é possível afirmar a necessidade da continuidade do trabalho e a construção gradativa da prática plural da inclusão social - o término da participação no grupo de convivência não pode "parar tudo", interrompendo passeios, relacionamentos, transformando negativamente $o$ cotidiano e a vida dos usuários.

As práticas em saúde mental devem fomentar a ampliação da rede social de apoio dos usuários e o fortalecimento gradual de laços diversos na comunidade. Tal tarefa somente acontecerá com ações conjuntas entre diferentes equipamentos e atores sociais.

Na prática do grupo de convivência, ainda se encontram alguns obstáculos. Atualmente há dificuldade em ampliar vagas para comunidade em geral, visto a demanda de atendimento na área da saúde mental. Está em processo a ampliação gradual das ações para a comunidade externa à instituição, procurando garantir não só a circulação e participação social de sua população alvo, mas também a vivência plural e diversa mesmo dentro do grupo.

FERRO, L. F.; CARDOSO, M. M.; FEDATO, G.; FRACARO, C. C. Convivial Group and Mental Health: user's perspective and the experience of Occupational Therapy Course of Federal University of Paraná. Rev. Ter. Ocup. Univ. São Paulo, v. 23, n. 2, p.146-152, maio/ago. 2012.

ABSTRACT: The current public policy on mental health direct their equipments and actions in order to build the social inclusion of the target population. One of the fruitful devices in this context is the convivial groups. With the intention to invest in the social inclusion of the users, a convivial group has been created through a partnership between the course of Occupational Therapy of the Federal University of Parana and Arnaldo Gilberti Association, located in city of Curitiba. In order to present a three years experience report, an qualitative-exploratory field research has been conducted in 2011. As technique for data collection, unstructured interviews were used on 11 individuals of the group. It was observed the importance of the device to provide encounters, thereby increasing the social support network of the users and their relationship with their territory. As problems for participation in the group, it could be seen the lack of family support and a still present fragility to conquer the group's autonomy. It's underlined, however, the need for close surveillance of the group by professionals as well as the continuity of the intervention as strategies to effectively provide social inclusion to the users of mental health services.

KEY WORDS: Mental health; Occupational therapy; Sensitivity training groups; Delivery of health care; Heaalth services; Public health. 


\section{REFERÊNCIAS}

BALLARIN, M. D. G. A. Algumas reflexões sobre grupos de atividades em Terapia Ocupacional. In: PÁDUA, E. M. M., MAGALHÃES, R. V. (Orgs). Terapia ocupacional: teoria e prática. São Paulo: Papirus, 2003. p. 62-76.

BAZHUNI, N. F. N. Circunscrevendo o campo diverso, diferente e divergente do acompanhamento terapêutico. São Paulo: Biblioteca 24horas, 2011.

BOCCARDO, A. C. S.; et al. O projeto terapêutico singular como estratégia de organização do cuidado nos serviços de saúde mental. Rev. Ter. Ocup. Univ. São Paulo, v. 22, n. 1, 2011.

BORGES, P. L. C.; et al. Perfil dos idosos freqüentadores de grupos de convivência em Belo Horizonte, Minas Gerais, Brasil. Cad. Saúde Pública, v. 24, n. 12, 2008.

BRASIL. Ministério da Saúde. Legislação em saúde mental: 1990-2004. 5a. ed. Brasília, 2004a.

BRASIL. Ministério da Saúde. Saúde mental no SUS: os centros de atenção psicossocial. Brasília, 2004b.

BRASIL. Ministério da Saúde. Guia prático de matriciamento em saúde mental. Brasília, 2011.

CARNEIRO, N. G. O.; ROCHA, L, C. O processo de desospitalização de pacientes asilares de uma instituição psiquiátrica da cidade de Curitiba. Psicol. Ciên. Profissão, v. 24, n. 3, p. 66-75, 2004.

FONSECA, M. A. A prática do terapeuta ocupacional em saúde mental a partir de uma perspectiva não excludente e de respeito às diferenças. In: DRUMOND, A. F.; REZENDE, M. B. (Org). Intervenções da terapia ocupacional. Belo Horizonte: Editora UFMG, 2008. p.71- 94.

DESSEN, M. A; BRAZ, M. P. Rede social de apoio durante transições familiares decorrentes do nascimento de filhos. Psicol.
Teoria Pesq., v. 16, n. 3, p. 221-231, 2000.

LOPES, I. C. Centros de convivência e cooperativa: reinventando com arte agenciamentos de vida. In: FERNANDES, M. I.; SCARCELLI, I. R.; COSTA, E. S. (Orgs.). Fim de século: ainda manicômios? São Paulo: IPUSP, 1999. p.139-62.

MARCONI, M. A.; LAKATOS, E. M. Fundamentos de metodologia científica. 6a. ed. São Paulo: Atlas, 2007.

MANGIA, E. F.; et al. Acolhimento: uma postura, uma estratégia. Rev. Ter. Ocup. Univ. São Paulo, v. 13, n. 1, p. 15-21, 2002.

MANGIA, E. F.; MURAMOTO, M. Redes sociais e construção de projetos terapêuticos: um estudo em serviço substitutivo em saúde mental. Rev. Ter. Ocup. Univ. São Paulo, v. 18, n. 2, 2007.

OLIVEIRA, G. N. O projeto terapêutico como contribuição para a mudança das práticas de saúde. Campinas, SP, 2007. Dissertação (Mestrado) Universidade Estadual de Campinas. Faculdade de Ciências Médicas, Campinas, 2007.

SARACENO, B. A concepção de reabilitação psicossocial como referencial para as intervenções terapêuticas em saúde mental. Rev. Ter. Ocup. Univ. São Paulo, v. 9, n. 1, p.26-31, 1998.

SÃO PAULO. Secretaria Municipal da Saúde. Acolhimento: o pensar, o fazer, o viver. São Paulo, 2002.

SILVA, G.; SANTOS, M. A. Esquizofrenia: dando voz à mãe cuidadora. Estud. Psicol. Campinas, v. 26, n. 1, 2009.

SOUZA, M. H. N.; SOUZA, I. E.O.; TOCANTINS, F. R. A utilização do referencial metodológico de rede social na assistência de enfermagem a mulheres que amamentam. Revista Latino-Amer. Enferm., v. 17, n. 3, 2009.

WEIL, S. O enraizamento. São Paulo: EDUSC, 2001.

YIN, R. K. Estudo de caso: planejamento e métodos. 4a. ed. Porto Alegre: Bookman, 2010.

Recebido para publicação: 06/02/2012

Aceito para publicação: 28/06/2012 